\title{
CONCEITO ANÁTOMO-FISIOLÓGICO DO LOBO OCCIPITAL
}

\author{
M. Caetano de Barros * \\ A. CaRDoso ** \\ G. HOLANDA ***
}

O lobo occipital tem os seus limites convencionalmente traçados, na face medial, pela cisura parieto-occipital continuada por uma linha imaginária que se dirige para baixo até encontrar a incisura pré-occipital. Na face lateral os limites são menos nítidos e indicados por uma linha que une o ponto mais elevado da cisura parieto-occipital à incisura pré-occipital. A cisura mais importante é a calcarina, situada na face medial, estendendo-se da extremidade posterior do polo occipital até a cisura paríeto-occipital, e prolongandose, em seguida, um pouco para diante e para baixo com cisura calcarina anterior. $\mathrm{Na}$ face lateral pode existir uma cisura - a occipital lateral - ou, às vêzes duas, uma superior e outra inferior.

Áreas - De acôrdo com o mapeamento cortical de Brodmann distinguemse, no lobo occipital, a área 17 (córtex visual ou área estriada, situada nas vertentes superior e inferior da cisura calcarina e a área 18 (córtex de associação visual) ou área paraestriada, ocupando as regiões adjacentes à área 17. Em tôrno da área 18 está a área 19 (periestriada) que se extende pelas porções mais posteriores dos lobos parietal e temporal, nas suas faces dorsolateral e ventro-medial. A área 19 tem importantes funções associativas, sobretudo com a área 18 , particularmente nos movimentos de seguimento optocinético e fixação dos olhos.

A superfície coberta pela área 17 é estimada diferentemente, variando de 20,4 a $45 \mathrm{~cm}^{2}$ (Crosby, Humphrey e Lauer ${ }^{7}$ ), podendo representar $3,2 \%$ de todo o córtex cerebral. O córtex estriado é delgado $(1,45$ a $2,2 \mathrm{~mm}$ de espessura) e classificado como córtex homogenético ou isocórtex porque mostra laminação em 6 camadas. Como estas não são, todavia, bem evidenciáveis é chamado heterotípico e do tipo granular. Assim, o córtex visual é um isocórtex heterotípico ou koniocortex heterotípico (Bayley e Bonin ${ }^{1}$ ). A área 18, pelo fato de ser um tipo transicional, é classificada como parakoniocórtex. Os limites entre as áreas 18 e 19 são difíceis de estabelecer, sobretudo na face lateral do hemisfério.

Relatório apresentado ao IV Congresso Brasileiro de Neurologia (Pôrto Alegre 5 a 9 de julho de 1970): * Professor Titular de Clínica Neurológica e Neurocirúrgica da Faculdade de Medicina da Universidade Federal de Pernambuco; ** ExProfessor da Anatomia da Faculdade de Ciências Médicas de Pernambuco; *** Auxiliar de Ensino da Clínica Neurológica e Neurocirúrgica da Faculdade de Medicina da Universidade Federal de Pernambuco. 
Do ponto de vista mieloarquitetônico o córtex visual apresenta aspectos característicos, particularmente no que se refere à agregação de fibras brancas à estria de Baillarger que, assim, engrossa e forma a estria de Gennari de onde advém a designação de área estriada dada ao córtex visual. A estria de Gennari parece ser formada por uma combinação de fibras de projeção visual e fibras de associação.

A área 17 recebe os impulsos vindos através de vias especificas (feixe genículo-calcarino ou radiações ópticas); por intermédio de fibras de associação, transitariam estes impulsos para a área 18, tornando-se conscientes. A área 19 estaria conectada com as áreas 17 e 18 e suas funções, bem mais complexas, se relacionariam com reconhecimento, associação visual, revisualização, visão das côres, tamanho e forma dos objetos e orientação espacial. Além disto, a área 19 representaria uma área de integração do sistema visual com os outros sistemas, recebendo impulsos de todo o córtex e sua atividade teria também efeito supressor sôbre a atividade dos dois hemisférios (Von Bonin, Garol e Mc Culloch ${ }^{3}$ ).

Conexões - As conexões do lobo occipital são extremamente ricas, representadas pelo trato geniculo-calcarino, fasciculos de projeçāo, feixes de associação e fibras comissurais que estabelecem ampla comunicação do tipo vai e vem, não só com outras estruturas funcionais à distância como entre as áreas do próprio lobo.

O tracto geniculo-calcarino ou radiação óptica tem origem no corpo geniculado lateral e termina no cortex estriado. As fibras superiores nascem na parte medial do corpo genlculado lateral, se dirigem para traz, passam por cima do corno occipital do ventriculo lateral e terminam no lábio superior da cisura calcarina; estas fibras correspondem aos quadrantes retinianos periféricos superlores (fibras da retina temporal homolateral e da retina nasal controlateral). As fibras inferiores têm origem na parte lateral do corpo geniculado lateral, se dirigem inicialmente um pouco para diante e para fora, dispersando-se na substância branca do lobo temporal e, depois, retomam direção caudal, passando por debaixo do corno occipital do ventriculo lateral, para terminarem no lábio inferior da cisura calcarina; estas fibras correspondem aos quadrantes retinianos periféricos inferiores (fibras da retina temporal homolateral e da retina nasal controlateral). O arranjo destas fibras contornando a ponta do corno temporal (a alca de Meyer) é hoje questionável. Finalmente, as fibras maculares emergem da porção dorsal e intermediária do corpo geniculado lateral, ocupam a parte central da radiação óptica e vão se projetar na parte mais caudal do córtex estriado. As metades superior e inferior destas fibras maculares, correspondem, respectivamente, aos quadrantes superiores e inferiores da mácula.

A projeção das fibras da radiação optica no córtex estriado obedece à seguinte sistematizaçāo: as fibras da visão periférica se projetam no $1 / 3$ mais rostral dos lábios da cisura calcarina; as da visão paramacular no seu 1/3 médio; as da visão macular no $1 / 3$ caudal, embora alguns admitam que parte destas últimas fibras possa terminar no 1/3 médio. Não há acôrdo entre os autores sôbre os detalhes da distribuiçāo final destas fibras no córtex visual, mas muito provavelmente eles terminam na IV camada, que corresponde à lâmina granular interna e inclui a camada das grandes e pequenas células estreladas (Kleist, 1926).

Embora quase todos os autores estejam de acôrdo em que há perfeita correspondencia entre a retina, particularmente a mácula, e a terminação de suas fibras no córtex visual, o registro cortical das respostas a estimulos retinianos sugere que as aferências visuais especificas se espalham para vários pontos do córtex cerebral possivelmente por intermédio de colaterais das fibras da radiação óptica. Assim sendo, a terminação "ponto a ponto" deve ser entendida como focos onde há maior densidade de superposição de ramificaçōes das aferências visuais. 
O córtex estriado nos dois hemisférios contém aproximadamente 1.400 milhōes de células nas quais se projetam cêrca de dois milhões de fibras ópticas vindas dos dois olhos, resultando daí enorme e imediata ampliação dos impu!sos nervosos que chegam à área cortical visual.

A representação macular no córtex visual tem constituido motivo de discrepância entre os autores desde longa data. De seu perfeito conhecimento resultaria a explicação correta para o fenômeno da poupança da visão macular nas hemianopsias conseqüentes a certas lesões occipitais. Alguns autores admitem que a mácula tem uma representação cortical difusa, outros que ela está representada bilateralmente, enquanto que um terceiro grupo (Polyak ${ }^{1 .}$ e Spalding ${ }^{20}$ ) sustenta que as metades homónimas das duas máculas se projetam em um mesmo hemisfério. Segundo Crosby e col. ' é anatòmicamente incerto que as radiações ópticas tenham projeção bilateral no córtex visual, embora existam fibras comissurais através do corpo caloso conectando a área 18 de um lado à área 18 contralateral. Também não encontra base anatômica a teoria da representação cortical difusa da visão macular. Para Dubois-Poulsen * a conservação macular é apenas um caso particular de conservação da linha média.

São numerosos os fascículos, feixes e fibras de associação que estabelecem comunicação não só entre as áreas do próprio lobo occipital como também com áreas distantes de todos os lobos cerebrais.

Desde longa data que a existencia destas vias tem sido demonstrada pela simples dissecção macroscópica completada por verificaçōes anátomo-patológicas, em briológicas e experimentais, mediante diferentes técnicas histológicas das quais se destacam as de coloração argêntica. Mais recentemente os métodos neuronográficos e as refinadas técnicas de microfisiologia, particularmente o registro da atividade neuronal isolada pela implantação de microelectrodos corticais e até intracelulares, ajuntaram enorme acêrvo de conhecimentos, inclusive no que diz respeito ao sentido em que se faz a condução.

Dêstes estudos ressalta a conclusão de que estes feixes, mesmo considerados anatomicamente como constituidos por fibras individualmente longas, são, na sua maioria, formados por vários componentes de fibras curtas ou internunciais com múltiplas sinapses. Tornou-se também evidente que predomina, nestas vias de associação, uma direção de influxo do tipo "vai e vem" e, ainda mais, que elas não são unidades nem anatômicas nem funcionais isoladas, mas devem ser consideradas como parte de um sistema de intercomunicação entre vários setores do sistema nervoso.

Para propósitos descritivos mencionaremos, em primeiro lugar, os principais fascículos de orientação longitudinal, presentes nos primatas e representados pelos fasciculos longitudinal superior e o inferior, occipito-frontal (ou fronto-occipital) superior e o inferior e também o cingulo. Éstes fascículos e sua significação têm sido interpretados de diferentes maneiras.

Contudo alguns dêles, seguramente os fasciculos longitudinal superior e occipitofrontal inferior, estabelecem comunicaçoes entre as áreas óculo-motoras frontais (áreas 8 e 9) e as áreas occipital e pré-occipital (áreas 18 e 19). Estas, por sua vez, mantém romunicaçoes reciprocas, assim como com suas homólogas do lado oposto, com a área $17 \mathrm{e}$, por intermédio das vias de projeção, com os núcleos óculomotores.

Experiências mediante estimulação e ablacão destas áreas, assim como os dados fornecidos pela sua patologia, indicam que elas integram os estimulos visuais e permitem a fixacão do olhar sôbre os objetos (Recondo, 1967). Isto resulta em movimento ocular adaptado que tem, como consequiência, a formação da imagem na fóvea retiniana e permitindo, assim, uma visão correta. Experimentalmente a destruicão das áreas 18 e 19 determina a perda dos movimentos oculares de seguimento e do nistágmo optocinético. Uma lesāo do fascículo occipito-frontal inferior, interrompendo as conexōes entre as áreas óculo-motoras frontais e as áreas óculomotoras occipitais, poderá impedir que o individuo fixe voluntàriamente um objeto 
que lhe é apresentado, embora os movimentos voluntários sob comando sejam normais para outros estimulos que não os visuais e também os automatimos visuo-motores estejam conservados (Crosby e col. ${ }^{n},{ }^{\top}$ ).

O fasciculo longitudinal inferior interconecta o córtex occipital, tanto medial (cuneus e língula), como lateral, com o córtex dos giros temporais superior, médio, inferior, fusiforme e, possivelmente, também o giro hipocampal (Crosby e col. i). Esta via, provavelmente polisináptica, que também comporta algumas fibras se estendendo até o córtex parietal, propicia múltiplas associaçōes audio-visuais (Crosby $\left.{ }^{a}\right)$. Tem sido mencionada a possibilidade de que esta associação funcional occipitotemporal se faça também através de circuitos reciprocos tálamo-corticais.

$O$ cingulo, que constitui grande parte da substancia branca do giro cingulo, se estende da área parolfatória até o hipocampo, circudando o corpo caloso e estabelece múltiplas comunicações, entre as quais, provavelmente, com o cúneo.

Afora êstes fascículos de longo trajeto encontram-se numerosos outros, assim como fibras curtas de associação intra ou sub-corticais, conectando reciprocamente áreas tamporais, occipitais com áreas vizinhas e também as próprias áreas occipitais entre si.

Esta complexa e rica rêde de associação no próprio lobo occipital está representada, principalmente, pelo fasciculo occipital lateral, pelas fibras transversas do cúneo e da lingula, fibras verticais occipitais, estrato calcarino, estrato do cúneo, estrato da lingula.

Fibras comissurais interconectam primàriamente áreas dos dois lobos occipitais através do esplenio do corpo caloso. Estas fibras estabelecem comunicação entre as áreas 18 e 19 dos dois lobos. Vários autores, estudando os efeitos da secção do esplênio do corpo caloso em macocos ( $R$. Meyers, Bailey, Von Bonnin e Mc Culloch ${ }^{3}$ ) e no homem (Valkenburg ${ }^{23}$ ) chegaram a conclusão de que não há fibras transcalosas conectando o cortex estriado tanto no macaco como no homem. Brodal: participa da mesma opiniāo.

A área periestriada poderia fazer parte de um centro integrativo amplo, incluindo também o córtex temporal, ou talvez funcione como uma estação sináptica que transmita impulsos visuais primários a centros mais elevados, possivelmente o lobo temporal.

Fisiologic - Certas partes das áreas 18 e 19, quando estimuladas eletricamente, determinam desvio conjugado dos olhos para o lado oposto a outras provocam desvios oculares oblíquos para cima e para baixo. Os primeiros movimentos resultam de impulsos veiculados pelo fasciculo córtico-tegmental que, partindo de zonas occipitais e pré-occipitais, atravessa a porção retrolenticular da cáfsula interna, cruza o pulvinar, faz parcialmente sinapse no colículo superior e se dirige dorsalmente para o tegmento, onde algumas de suas fibras fazem sinapse. Em seguida o fascículo crtico-tegmental, cruza a linha média em direção ao núcleo do VI nervo contra-lateral onde faz sinapse $e$, provavelmente, entra em relação também com o núcleo parabducens (Recondo, 1967).

Outros impulsos que, partindo das referidas zonas, condicionam os desvios oculares oblíquos para cima e para baixo, seguem o fascículo córtico-pretectal ou córtico-tectal interno ou córtico-mesencefálico e se projetam, pelo sistema córtico-tectal interno, no colículo superior. Dai, sem constituirem um feixe bem individualizado, algumas fibras contornam a substância cinzenta periaquedutal e vão terminar nos núcleos do III nervo homo e contralateral (Crosby, Humphrey e Lauer ${ }^{\tau}$ ). 
Alguns investigadores têm sugerido que as áreas 18 e 19 também enviam projeções aos centros vestibulares. Bremer ${ }^{4}$, Murata e col. ${ }^{14}$, Lomo et Mollica ${ }^{13}$, fazendo registros por técnicas de integração e em estudos microfisiológicos levados a efeito em gatos e coelhos, evidenciaram, ao nível do córtex visual, respostas a diferentes estímulos somastésicos, auditivos e vestibulares, assim como suas convergência com os estímulos visuais.

$\mathrm{Na}$ mesma ordem de fatos e em apôio ao conceito de que o lobo occipital é, para o sistema óptico, apenas um componente em íntima sinergia com outros sistemas sensoriais e tônicos, alinham-se as conclusões de Breonstein ${ }^{2}$ sôbre a teoria de Von Hornbostel em relação à percepção. Boernstein pretende que ó sistema óptico está em intima e ampla integração com o sistema regulador do tonus aumentando a acuidade para ver contornos, localização dos objetos no espaço e profundidade. A diminuição do tono muscular reduz a acuidade visual; reciprocamente, a luz e a escuridão aumentariam e diminuiriam, respectivamente, o tonos muscular.

Outros estímulos não primariamente visuais mas que, de acôrđo com a teoria de Von Hornbostel, podem ser categorizados no processo "claro-escuro", em condições apropriadas constituiriam estímulos adequados para o sistema óptico, precisamente porque não entram no organismo pela via retinocortical. Estes estímulos convergiriam para uma "via final comum" no mesencefálo e, daí, através de um sistema retículo-hipotálamo-cortical, atingiriam o campo óptico (Boernstein, 1967). E o princípio do "efeito auditivo" de processos não ónticos sôbre o sistema óptico.

Estes dados demonstram como é complexo o problema da compreensão da visão em têrmos anátomo-fisiológicos.

As numerosas mensagens relativas à forma, côr, movimento e profundidade dos objetos são recebidos, veiculadas, elaboradas, integradas e interpretadas por estas estruturas, de forma a permitirem uma percepção visual normal.

Vascularização - A irrigação arterial do lobo occipital depende essencialmente da artéria cerebral posterior ou mesencefálica que se desenvolve como um ramo da carótida interna mas que, no homem adulto, resulta usualmente da bifurcação da artéria basilar. Os ramos da artéria cerebral posterior que irrigam o lobo occipital são os terminais paríeto-occipital e calcarino, que caminham nas cisuras respectivas da face medial do lobo. A parte mais inferior desta mesma face também recebe irrigação da artéria temporal posterior ou têmporo-occipital, ramo da cerebral posterior. A artéria calcarina fornece irrigação para os dois lábios da cisura calcarina (área estriada), centro visual primário. As artérias parieto-occipital e temporal posterior nutrem as faces mediais ças áreas de associação visual.

$\Lambda$ face lateral do lobo occipital - áreas 18 e 19 - além da irrigação fornecida pelos ramos terminais destas mesmas artérias, pode receber nutrição de alguns terminais da artéria cerebral média que se anastomosam com os ramos da cerebral posterior. A área de projeção das fibras maculares da radiação óptica pode ser nutrida pela artéria calcarina ou pelo ramo temporal 
posterior da cerebral média que se anastomosam em grau variável. Alguns autores pretendem explicar a poupança macular nos casos de trombose da cerebral posterior pela suplência circulatória decorrente desta anastomose.

Como as anastomoses entre as artérias cerebral posterior e cerebral média parecem se fazer mais fàcilmente ao nível do cúneo do que do giro lingual, também se tem pretendido explicar pelo mesmo mecanismo a poupança de uma área contígua à mácula, para baixo, ao longo do meridiano vertical, observada em alguns casos de obstrução bilateral da artéria calcarina.

Anastomoses arteriais - Variável de indivíduo a indivíduo e até de um hemisfério a outro, o território da artéria cerebral posterior é o menos extenso das três artérias cerebrais. Contudo as anastomoses entre os seus ramos, paticularmente as artérias paríeto-occipital e calcarina, e os ramos terminais da cerebral média na superfície lateral do córtex, podem ser facilmente demonstradas em preparações anátomo-radiológicas. Cateterizando-se a cerebral pos-
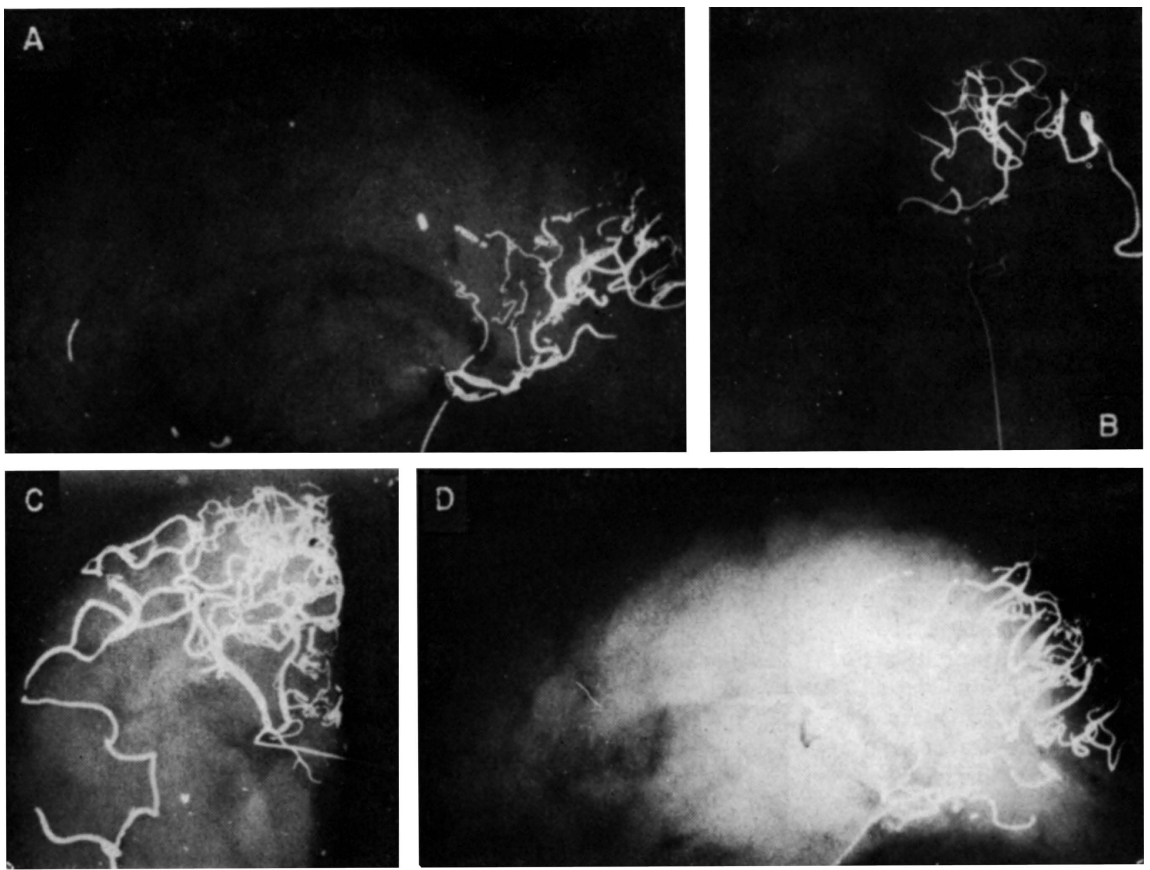

F'ıg. 1 - Em A, injeção de contraste na artéria cerebral posterior após ligadura de seus ramos temporais, em vista de perfil; em $B$, vista basal mostrando o inicio das anastomoses entre os ramos parieto-occipital da cerebral posterior e os ramos da cerebral média; em C, vista basal mostrando o progressivo enchimento retrógrado da cerebral média através da cerebral posterior; em $D$, mesmo aspecto que em $C$ visto de perful. Vide continuação na figura 2. 
terior, mesmo após a emergência dos seus ramos temporais, a injetando-se contraste lentamente, pode-se acompanhar, em radiografias seriadas, o enchimento das artérias paríeto-occipital e calcarina, e, através destas, suas amplas anastomoses com alguns ramos da cerebral média (Fig. 1). Continuando-se a injeção de contraste êste vai visualizando, por via retrógrada, grande parte do território da cerebral média assim como da cerebral anterior e termina por sair pela carótida (Fig. 2). O enchimento simultâneo e progressivo dos

Fig. 2 - Continuação da figura 1. $\operatorname{Em} A$, fase mais avançada do enchimento em vista basal; em $B$, inicio do enchimento do tronco da artéria cerebral média em vista basal; em $C$, mesma fase que e'm $B$ em vista lateral; ein $D$, fase ulterior mostrando, $\epsilon m$ vista lateral, o enchimento de quase todo o sistema carotídeo pelo coritraste injetado na artéria cerebral posterior.
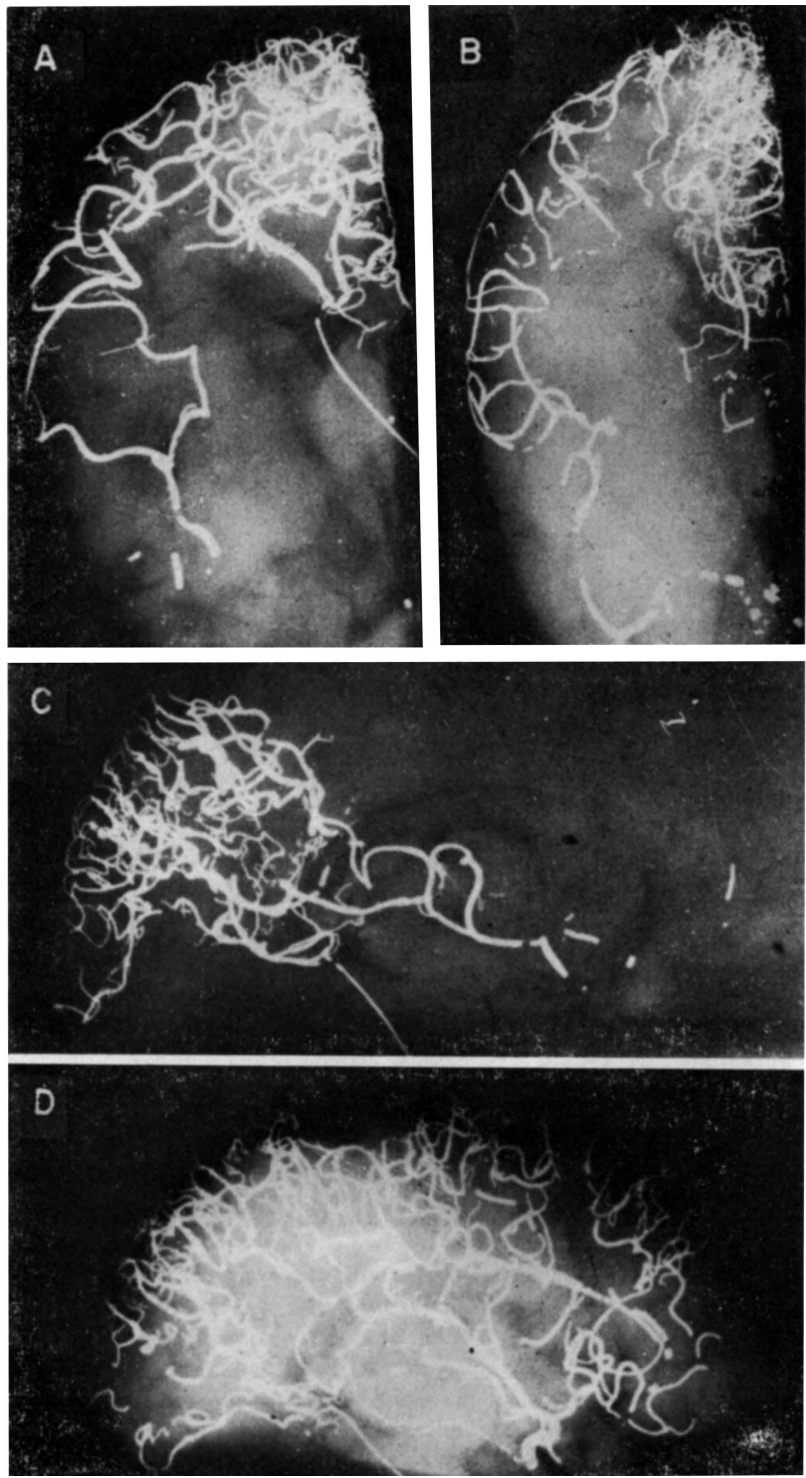
ramos mais posteriores das 3 artérias, através de cateteres colocados separadamente em determinados segmentos das mesmas, permite a visualização radiológica da rica rêde anastomtica que elas formam ao nivel do lobo occipital e áreas parietais vizinhas (Fig. 3).
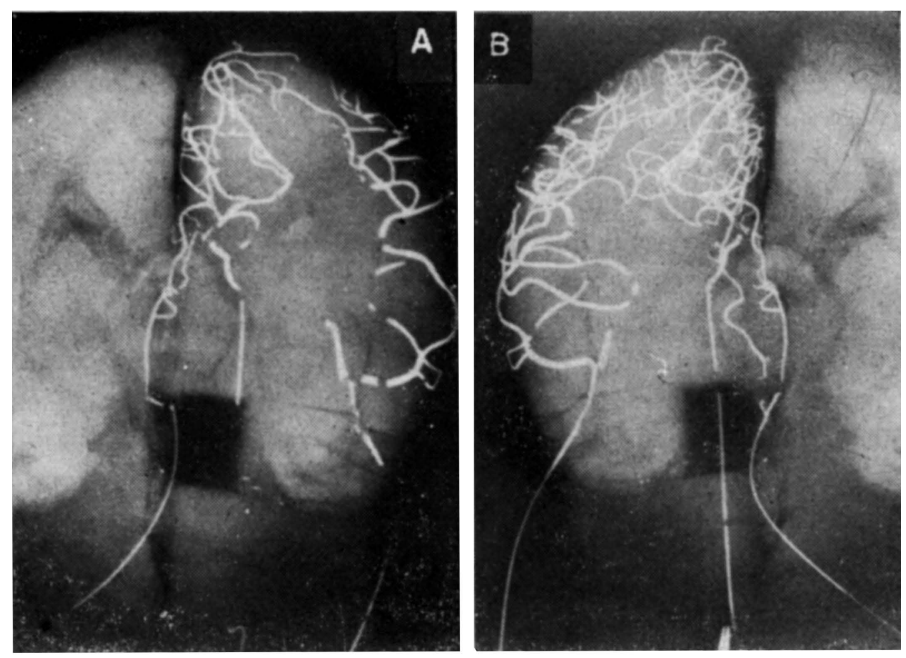

Fig. 3 - Em A, injeção simultânea de contraste através de catéteres colocados separadamente nas artérias cerebral anterior, cerebral média e cerebral posterior, em vista basal; em $B$, fase mais adiantadla do enchimento.

Estas anastomoses sāo aparentemente aptas a atenderem as necessidades básicas de irrigação do lobo occipital em caso de obstrução de alguns dos ramos da cerebral posterior que para lá se dirigem e, possivelmente, também nas obstruções dos ramos da cerebral média.

Contudo, como a dinâmica da circulação cerebral depende da ação combinada de muitos fatores, não se deve inferir, pela simples constatação anatômica de anastomoses "funcionantes" em condições artificais, que elas também o sejam ao vivo. De outra forma as isquemias cerebrais seriam excepcionais. As anastomoses corticais cerebrais representam o "reliquat" de uma disposição fetal na qual se observam arcos arteriais continuos unindo as três principais artérias cerebrais. No curso dos últimos meses da vida fetal as junções dos arcos desaparecem ou regridem para formar estreitas anastomoses (Lazorthes et al., 1961).

No córtex cerebral existe fina rede arteriolar sub-pial conectando as artérias entre si. Na pia mater não há capilares (Crosby, Humphrey e Lauer ${ }^{i}$ ). Das artérias e da rede arteriolar emergem finas e numerosas arteríolas que pentram no tecido cerebral. Sāo vasos curtos, médios e longos, particularmente no neo-córtex. Segundo Lazorthes e Comes ${ }^{12}$ as artérias curtas são 
delgadas, dão poucas colaterais e terminam, provavelmente na II e III camadas; as médias terminam nas IV e $\mathrm{V}$ camadas e dão algumas colaterais perpendiculares; as longas são também as mais volumosas e atingem a substância branca. As áreas de maior densidade celular possuem também maior riqueza vascular, sobretudo a área motora (tipo agranular) e a visual, coniocórtex (tipo granular). Lazorthes e Gomes ${ }^{12}$ assinalam ser perfeita a concordância entre a angioarquitetônica e a citoarquitetônica.

O débito sangüineo cortical parece apresentar variações topográficas significativas (Lazorthes et al., 1967) e aparentemente guarda relações com a angioarquitetura. Assim, as diversas áreas corticais apresentam variações topográficas do fluxo sangüíneo. Lazorthes et al. (1968), realizando medidas dêste fluxo mediante injeções intraparenquimatosas de gaz inerte radioativo, confirmaram até certo ponto estas variações, embora fazendo a ressalva de que estas medidas não foram feitas em condições fisiológicas. Os valores mais baixos foram encontrados nos lobo temporal e no giro precental $(74 \mathrm{ml} /$ $100 / \mathrm{min}$ ), enquanto que os mais altos foram encontrados nos lobos parietal $(110 \mathrm{ml} / 100 \mathrm{~g} / \mathrm{min})$ e occipital $(104 \mathrm{ml} / 100 \mathrm{~g} / \mathrm{min})$.

As veias do lobo occipital são pouco importantes pelo seu calibre e relativamente raras. Sua distribuição é irregular e não segue a das artérias. Elas podem formar um grupo superior que drena no seio longitudinal superior e um grupo inferior que drena no seio lateral. As veias da parte superior são as mais calibrosas e tomam direção rostro-medial para se juntarem às veias parietais a desembocarem no seio longitudinal, em ângulo agudo e. contra corrente; êste detalhe é considerado por alguns autores como dispositivo valvular da regulação venosa, mas o seu significado exato é ainda discutido. As veias da porção inferior da face medial do lobo occipital em geral se reunem em um só grupo e drenam no seio lateral ou no seio petroso superior (Lazorthes, 1961); algumas, antes de se lançarem no seio petroso superior (Lazorthes, 1961); algumas, antes de se lançarem no seio lateral se juntam às veias temporais da base. As da porção superior se dirigem de traz para frente e se juntam às parietais para se lançarem nas veias da face lateral e, di, no seio longitudinl superior. Algumas veias occipitais internas drenam na veia de Galino (Kaplan e Ford ${ }^{11}$ ), inclusive a chamada veia calcarina de Testut. Semelhantemente ao plexo arteriolar sub-pial, há um plexo de finas vênulas que interconecta as veias mais calibrosas (Crosby, Humphrey, Lauer ${ }^{7}$ ).

Cornos occipitais dos ventriculos laterais - O corno occipital ou corno posterior do ventrículo lateral apresenta forma e dimensões bastantes variáveis. Normalmente é curto e estreito e termina quase abrutamenta. Começa na porção posterior do "atrium" ou trígono do ventrículo lateral e se projeta no lobo occipital, "em dedo de luva", para traz e um pouco para a linha méđia, numa extensão que chega a atingir até $3 \mathrm{~cm}$ (Shanks \& Kerley ${ }^{18}$ ). Sua extremidade pode ser arredondada, globosa ou afilada, terminando em ponta. 
O corno occipital pode não existir ou ser rudimentar em um só ou nos dois lados. Rugiero ${ }^{17}$, revendo 100 pneumencefalogramas negativos, registrou $50 \%$ de casos de ausência dos cornos occipitais, $28 \%$ com um só como (21 esquerdos e 7 direitos), $14 \%$ com os dois cornos presentes e $8 \%$ com cornos hipoplásicos. Freqüentemente êles são assimétricos. Em estudos radiológicos feitos em cadáveres, utilizando combinadamente contraste positivo e ar, temos podido demonstrar algumas destas variações anatômicas: corno occipital extremamente desenvolvido, ausente em um só lado, arredondado, simétrico e afilado nos dois lados, com um lado afilado e outros arredondado, um lado bem desenvolvido e outro hipoplásico, ausente em ambos os lados e terminados em ponta (Fig. 4).
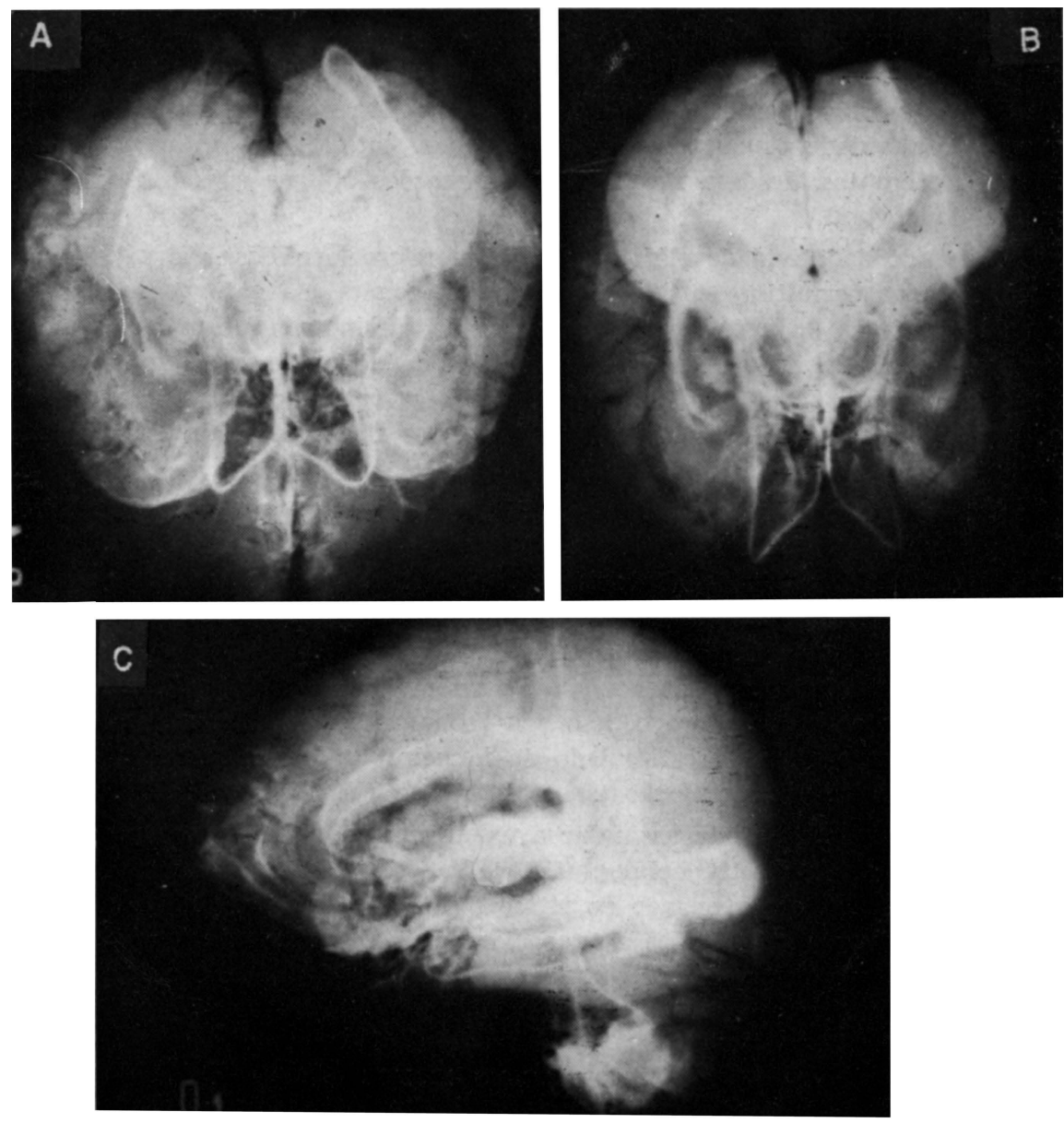

Fig. 4-Em A, corno occipital ausente em um só lado; em B, cornos occipitais simétricos e afilados em ambos os lados; em $C$, cornos occipitais arredondados. 
Nos seus limites com o trígono, na sua porção supero-medial, algumas vêzes podem ser vistas depressões ocasionadas por diferentes graus de desenvolvimento do "calcar avis" que corresponde à parte anterior da cisura calcarina, e do "forceps major". Taveras e Wood ${ }^{22}$ admitem que um maior desenvolvimento destas estruturas é a causa da obliteração de um dos cornos occipitais.

Sendo o corno occipital a única porção do sistema ventricular que apresenta elevado grau de variações em sua forma, estas devem ser bem conhecidas a fim de se evitar possiveis êrros de interpretação de algumas imagens pneumográficas.

Atividade elétrica do lobo occipital - Do ponto de vista das atividades elétricas, o lobo occipital tem sido estudado nos seus aspectos gerais, em participação com outras regiōes do cérebro, e nos seus aspectos mais ou menos específicos. Numerosos pesquisadores continuam a explorar o lobo occipital em diferentes situações, clínica e experimentalmente, no homem e em animais, quanto à atividade espontânea ou evocada por estimulação fótica e elétrica das vias aferentes, desde a retina até as radiações ópticas e, também, diretamente do córtex.

O estudo da atividade elétrica, mediante microeletródios, das células corticais isoladas permitiu identificar, no córtex occipital do gato, 5 tipos distintos de neurônios de acôrdo com sua ativação luminosa (Jung, Creutzfeldt e Grusser ${ }^{10}$ ). Estes neurônios que pulsam independentemente em condições fisiolgicas na ausência de estimulação, podem atuar sincronizados em conđições patológicas; sob estimulação, em condições fisiológicas alguns neurônios são ativados e outros inibidos.

O registro da atividade elétrica pela eletrencefalografia convencional mostra que embora se observem ritmos variados - alfa, beta e teta - o ritmo alfa é o mais importante das regiōes posteriores, occípito-parieto-temporais. Ao lados dêstes ritmos são registradas as ondas lambda que constituem uma atividade mais propriamente occipital (Rémond, 1960). As ondas lambda podem ser registradas na região occipital, em indivíduos adultos normais com os olhos abertos e desaparecem com o seu fechamento. Podem ainda aparecer quando o campo visual é estimulado de maneira uniforme, como ocorre, por exemplo, durante uma projeção cinematográfica (Y. Gastaut, 1951).

Por último, vale ainda assinalar a existência de ondas lentas posteriores, denominadas pelos electrencefalografistas franceses como ondas "pi", com a mesma topografia e reatividade do ritmo alfa. Estas ondas podem ser registradas em crianças até 14 anos e, excepcionalmente, em adultos jovens. Alguns autores têm procurado correlacionar êste grafoelemento com certos distúrbios de comportamento.

\section{CONSIDERAÇOESS FINAIS}

O estudo da anatomia funcional do lobo occipital põe em relêvo a necessidade de considerá-lo como parte de um sistema altamente complexo funcionando em conexão com quase todas as estruturas encefálicas. A síntese desta 
atividade é a percepção visual, a mais importante função sensorial cerebral. O estudo das disfunções do sistema visual e a sua interpretação fisiopatológica reforça e comprova o conceito acima.

Quando se analisam os prováveis mecanismos que dão origem aos sintomas neuro-psicológicos e síndromes resultantes das lesões do lobo occipital e suas conexões, chega-se à conclusão de que estes mecanismos possivelmente se efetuam nos modêlos dos servo-mecanismos cibernéticos.

Desde os sintomas e sinais mais elementares, como as hemianopsias e demais defeitos do campo visual, num gradiente de complexidade passando pela poliopia, metamorfopsias, dismetropsia, alucinações visuais, cegueira cortical, até os mais complexos como a palinopsia, agnosias visual e espacial, as sindromes de Anton (anosognosia para a própria cegueira) e de Ballint (paralisia psiquica do olhar), todos êstes distúrbios resultam da combinação de alterações anatômicas e dinâmico-funcionais.

As estruturas dinâmicas das diferentes áreas corticais e suas conexões contribuem para a formação de um sistema funcional que trabalha em conjunto. A destruição de qualquer um dêstes componentes desintegra o sistema, perturbando sua função e determinando os sintomas e sinais.

Como em todo sistema dinâmico, as alterações menores podem ser compensadas pela entrađa em ação dos mecanismos estabilizadores representados pelos circuitos de "feed-back" negativos, de importância já conhecida nos sistemas de contrôle da medula e provavelmente também no cérebro (Taylor, 1965). Quando, por qualquer circunstância, êstes mecanismos de contrôle não atuam a estabilidade fica comprometida.

A desorganização das funções vísuo-óculo-motoras, que caracteriza a sindrome de Balint tem recebido recentemente interpretação à base de conceitos cibernéticos. Nesta síndrome o "feed-back" negativo, necessário à execução eficiente das funções óptico-motoras seria transformado em "feed-back" positivo. "Assim, os estímulos visuais, em vez de facilitação, levariam a uma progressiva deterioração da execuções óculo-motoras, e reciprocamente" (Porowsky).

Embora a aplicação dos principios de cibernética na interpretação dos mecanismos da dinâmica do sistema nervoso devam ser apreciados cautelosamente, há, sem dúvida, grande atração entre os neurofisiologistas para utilizá-los. Estes conceitos favorecem também, de alguma forma, a compreensão dos mecanismos que integram as diferentes estruturas funcionais do sistema óptico.

Aqui também se aplica o conceito das "totalidades" ou "Gestalten". Certas estruturas, sobretudo as orientadas para uma função, não podem ser referidas como a soma de suas partes, independentes entre si mesmas; seu funcionamento depende da relação existente entre as atividades de seus componentes permitindo a constituição de "totalidade", isto é, de uma unidade funcional e não de simples agregado (Seguin, 1947). O conceito parece válido na sua aplicação ao sistema óptico. 
Com êste relato pretende-se fazer uma revisão sumária de alguns dos principais aspectos da organização anátomo-funcional do lobo occipital e da "posição" no sistema visual. Só do conhecimento minuncioso destas estruturas é que se poderá esperar uma interpretação mais correta das suas disposições, isto é, dos sintomas. Importantes conquistas têm sido feitas nestes últimos anos no que tange à anatomia funcional do lobo occipital, mas certamente muito resta ainda a conhecer. As atualizaçōes valem menos por si mesmas do que pelo interesse que possam despertar na busca de novos progressos nos nossos conhecimentos.

\section{R E S U M O}

Apenas do ponto de vista estritamente anatômico o lobo occipital pode ser delimitado com relativa facilidade. Aparentemente constitui uma unidade morfológica, séde de estruturas bàsicamente relacionados com a percepção visual, aí entendidos também certos mecanismos integrativos óculo-motores que, em última análise, não são senão componentes dêste complexo fenômeno perceptivo.

Depois de revistos alguns detalhes da anatomia convencional do lobo occipital (limites, área cortical estriada, peri-estriada e para-estriada) é feita uma tentativa, à base de estudo da literatura, no sentido de indicar as principais conexões destas áreas (radiações ópticas, feixes de associação, fibras de projeção e fibras comissurais) com diferentes estruturas do sistema nervoso central. A vascularização do lobo occipital é revisada com o auxilio de preparações anátomo-radiológicas seriadas e seletivas de diferentes troncos arteriais, nas quais se constatam intercomunicações entre os setores "terminais" dos sistemas das artérias cerebral posterior, média e anterior. Algumas variações morfológicas dos cornos occipitais são também postas em evidência com recursos de técnicas anátomo-radiológicas.

Todavia, dados puramente anatômicos não são suficientes para compreensão das funções psico-fisiológicas do lobo occipital que pode ser conceituado como parte de um sistema perceptivo - o sistema óptico - altamente complexo, funcionando integradamente com múltiplos sectores do sistema nervoso e envolvendo diferentes mecanismos. Muito provàvelmente êste sistema, à maneira de muitos outros sistemas biológicos, está composto de vários circuitos mutuamente conjugados agindo sob o princípio de servo-mecanismos, devendo sua ação ser encaixada dentro do conceito das "totalidades" (Gestalten), cuja funcionalidade não deriva da soma dos seus componentes, mas da relação funcional que estes mantém entre sí para a atuação conjunta. Como toda função superior, a função visual não pode ser estritamente localizada e resulta da integração de estruturas funcionando conjugadamente.

Melhor entendimento desta função vem sendo progressivamente favorecido mediante o estudo da patologia, dos resultados da neurocirurgia experimental, dos efeitos de certas ablações neurocirúrgicas no homem e, sobretudo, das atuais referinadas técnicas eletro-neurofisiológicas. Malgrado êstes avanços há ainda muitos aspectos mal definidos aguardando melhores elucidações. 
S U M M A R Y

\section{Functional anatomy of the occipital lobe}

Only from a strictly anatomical point of view the occipital lobe can be traced with relative facility. Apparentely it constitues a morphological unit representing the site of structures basically related to visual perception, therein included some other oculo-motor integrative mechanisms which are nothing else but components of this complex perceptive phenomenon.

The principal parts of the conventional superficial anatomy of the occipital lobe (striated, peristriaded and para-striated cortical areas) and the principal connections (optical radiations, association tracts, projection and commissural libers) with different structures of the nervous system are indicated. The vascularization of the occipital lobe is revised by the use of serial and selective anatomic-radiological preparations of the different arterial trunks in which it could be verified wide intercommunications between the terminal sectors of posterior, medial and anterior cerebral arterial systems. Some morphological variations of the occipital horns of the lateral ventricles are emphasized.

However purely anatomic data are not sufficient enough for the understanding of the psycho-physiological functions of the occipital lobe which has to be considered as a part of a perceptive highly complex system. Very probably this system in the same way of many other cerebral ones is composed by several circuits mutually conjugated acting under the principle of servomechanisms and ruled by the conception of totality (Gestalten) whose funccionality does not depends on the sum of its components but on the relationships that the different parts mantain among themselves. This means that, as in every superior cerebral function, the visual activity cannot be strictly localised as it results from the integration of many structures working harmoniously.

A better understanding of this function is being progressivly increased by the study of pathology, by the results of experimental neurosurgery and neurosurgical ablations in man and, above all, by experimental rechearches based on refined electroneurophysiological techniques. Nevertheless, in spite of some advances there are still many aspects waiting for further elucidation.

\section{R E F E R N C I A S}

1. BAILEY, P. \& VON BONIN, G. - The Isocortex of man. University of Illinois Press, Urbana, 1951.

2. BOERNSTEIN, W. S. - Opitic pereeption and optic imageries in man. Their roots and relations studied from the viewpoint of biology. Intern. J. Neurol. 6:147, 1967.

3. VON BONIN, G.; GAROL, H. W. \& Mc CULLOCH, W. S. - The funcional organization of the occipital lobe. Biol. Symposia 7:165-192, 1942.

4. BREMER, F. - Analyse oscillographique des réponses sensorielles des écorces cérébrale et cérebelleuse. Rev. neurol. (Paris) 87:65, 1952. 
5. BRODAL, A. - Neurological Anatomy in Relation to Clinical Medicine. Second edition. Oxford University Press, London-Toronto, 1969.

6. CROSBY, E. C. - Anatomie du lobe occipital et anatomie comparée des vois visuelles. In: Les Grandes Activités du Lobe Occipital. Alajouanine et al. ed. Masson et Cie., Paris, 1960.

7. CROSBY, E. C.; HUMPHREY, T. \& LAUER, E. W. - Correlative Anatomy of the Nervous System. MacMilian Co., New York, 1962.

8. DUBOIS-PULSEN - Resumo in Excerpta Medica - Transations of International Congress of Ophtalmology (México, 1969).

9. GLONING, I.; GLONING, K. \& HOFF, H. - Neuropsychological Symptoms and Syndromes in Lesions of the Occipital Lobe and the Adjacent Areas. Gauthier Villars, Paris, 1968.

10. JUNG, R.; CREUTZFELDT \& GRUSSER, O. J. - Die Mikrophysiologie Kortikaler Neurone und ihre Bedeutung für die Sinnes und Hirnfunkionen. Deutsch. Med. Wschr. 82:1050, 1957.

11. KAPLAN, A. K. \& FORD, D. H. - The Brain Vascular System. Elsevier, Amsterdam-London-New York, 1966.

12. LAZORTHES, G. \& GOMES, A. F. - L'angioarchitecture arterielle de l'écorce cérébrale. Essai de systematisation par une technique personelle. Bul. Acad. Nat. Med. (Paris) 145:698, 1961.

13. LOMO, T. \& MOLICA, A. - Activity of single units in the primary optic cortex in the unanesthetized rabbit during visual, acoustic, olfactory and painful stimulation. Arch. Ital. Biol. 100:86, 1962.

14. MURATA, K.; CRAMER, H. \& BACH Y RITA, P. - Neuronal convergence of noxious, acoustic and visual stimuli in the visual cortex of the cat. J. Neurophysiol. 28:1223, 1965.

16. POLIAK, S. - The Retina. University of Chicago Press, Chicago, 1941.

17. RUGGIERO, G. - L'Encephalographie Fractionnée. Masson et Cie. Paris, 1957.

18. SHANKS, S. \& KERLEY, P. - A Text-book of X-Ray Diagnosis. H. K. Lewis, London, 1951.

19. SPALDING, J. M. K. - Wounds of the visual pathway: the visual radiation. J. Neurol. Neurosurg. Psychiat. 15:99, 1952.

20. SPALDING, J. M. K. - Wounds of the visual pathway: the striate cortex. J. Neurol., Neurosurg. Psychiat. 15:169, 1952.

21. STERIADE, M. - Physiologie des Voies et des Centres Visuels. Masson et Cie., Paris, 1969.

22. TAVERAS, J. M. \& WOOD, E. H. - Diagnostic Neuroradiology. Williams \& Wilkins, Baltimore, 1964.

23. VALKENBURG, C. T. - Experimental and pathologico-anatomical researches on corpus callosum. Brain 36:119, 1913.

Instituto de Neurologia e Neurocirurgia - Hospital Pedro II - 50000 Recife PE - Brasil. 